\title{
LA SUPREMA CORTE DE OBAMA
}

\section{THE OBAMA'S SUPREME COURT}

\author{
Mario MELGAR ADALID
}

RESUMEN: El presente artículo refiere el papel de la Suprema Corte en la organización política, jurídica, social y económica de los Estados Unidos. Barack Obama designó al primer juez asociado de la Corte. La enorme expectación de la noticia muestra la cultura jurídica de ese país. El presidente Obama declaró su visión sobre las cualidades liberales, democráticas y populares que debería reunir el designado. La decisión recayó en la jueza de apelación Sonia Sotomayor; el anuncio fue recibido con beneplácito por los liberales y con escepticismo por el conservadurismo. La Suprema Corte al interpretar la Constitución fija la ruta ideológica del sistema en su conjunto. ¿Debe tener un temperamento neutro o ideológico? ¿Debe la Suprema Corte ser un factor de cambio? ¿Lo debe ser de estabilidad institucional? ¿Debe su presidente tratar de alcanzar decisiones unánimes? ¿Las decisiones unánimes fortalecen o debilitan a una Corte Suprema?

Palabras clave: Suprema Corte de Estados Unidos, nombramiento de jueces, estabilidad institucional, conservadurismo judicial, liberalismo judicial.
ABSTRACT: This article refers the Supreme Court roll in political, juridical, social and economical organization of the United States of America. Barack Obama designed the first court's associated judge. The huge expectation of this news shows the judicial culture in that country. President Obama declared his vision of the liberal, democratic and popular qualities the designed judge should gather. The designation fell upon Appellation Judge Sonia Sotomayor; the announcement had been warmly received by the liberals and with skepticism by the conservators. When the Supreme Court interprets the Constitution, it sets the ideological route of the system as a whole. Should it have a neutral or ideological behavior? Should the Supreme Court be a change factor? Should it be of institutional stability? Should its President try to get unanimous decisions? Do those unanimous decisions strength or weak a Supreme Court?

Descriptors: United States' Supreme Court, Nomination of Judges, Institutional Stability, Judicial Conservatism, Judicial Liberalism. 


\section{INTRODUCCIÓN}

La Suprema Corte de los Estados Unidos juega un papel central en la organización política, jurídica, social y económica de ese país. Es considerada como la Corte paradigmática dentro de los sistemas jurídicos de las llamadas democracias occidentales. Es una Corte que no tiene influencias ni antecedentes históricos sobre los que sustente su desarrollo, el que obedece a la manera como se ha conformado el sistema político y jurídico de los Estados Unidos. El papel central de sus nueve integrantes es decidir lo que significa la Constitución. Cuando hay una duda sobre el sentido de una ley, o sobre si los actos ejecutados por el presidente o por el departamento de policía municipal están o no apegados a la Constitución, la Suprema Corte tiene la última palabra. Sus decisiones son definitivas, no pueden ser modificadas, salvo por decisiones futuras de la propia Corte o por una enmienda constitucional.

En los años previos al arribo de George W. Bush a la presidencia, la Suprema Corte de los Estados Unidos tuvo frente a sí, asuntos de la mayor importancia para ese país. A pesar de ser una institución que poco tiene que ver con los instrumentos de la democracia, su actuación ha sido sorprendentemente acorde con las expectativas de las mayorías. Los jueces de la Suprema Corte son designados exclusivamente por el presidente con la ratificación del Senado. No rinden cuentas a nadie pues su actuación es irresponsable de otros poderes. No están obligados a seguir los mandatos mayoritarios, pues son designados de por vida, sin que nadie les pida rendición de cuentas, lo que pretende garantizar su independencia. Pero si eso no fuera autoritario, el presidente de la Suprema Corte es designado por el presidente de los Estados Unidos con la aprobación del Senado.

Entre 1992 y 2005, la Suprema Corte marcó pautas que son plenamente coincidentes con una agenda popular liberal en asuntos cruciales como los relativos a raza, religión, aborto, género y facultades del gobierno federal. Lo anterior generó una contrarrevolución de los conservadores que se fue gestando en algunas escuelas de derecho, iglesias evangélicas y, a la llegada de los conservadores al poder, en la misma Casa Blanca. La agenda de este grupo ha sido constante: dar marcha atrás a Roe vs. Wade para permitir que los estados puedan prohibir el aborto, expandir el poder del Ejecutivo federal, acabar con las preferencias raciales que se diseña- 
ron con la finalidad de apoyar el proceso de integración plena de los afroamericanos, agilizar las ejecuciones de criminales, permitir las expresiones religiosas en la vida pública. Toda esta serie de cuestiones elementales de la vida social, económica y política de los Estados Unidos depende en muchas ocasiones de una sola persona, de un solo voto. ${ }^{1}$

Durante la celebración de una rutinaria conferencia de prensa en la Casa Blanca el vocero del gobierno de los Estados Unidos fue interrumpido por la aparición imprevista e intempestiva del presidente Barack Obama. "Lamento interrumpir la conferencia, pero el juez asociado Souter me informó telefónicamente (hacía solamente unos cuantos minutos) que tomó la decisión de retirarse de la Suprema Corte", dijo el presidente a los periodistas congregados. ${ }^{2}$

El presidente al agradecer los servicios del renunciante, señaló además que el juez Souter "demostró lo que significa ser un juez imparcial e independiente. Llegó a su sitial sin una ideología específica. Nunca buscó promover una agenda política". El presidente aprovechó la oportunidad ante los medios para dar el perfil del sucesor que propondría al Senado para sustituir al juez Souter, quien decidió renunciar para recuperar, según lo expresó él mismo, su libertad perdida en la ciudad de Washington. Dijo el presidente que buscaría alguien que entienda que la justicia no es únicamente algo relativo a una teoría jurídica abstracta o a las notas de pie de página del libro de casos. "La justicia es también la manera en que las leyes afectan la vida cotidiana de la gente, se refiere a cómo resuelven las personas sus diarias necesidades y el cuidado de sus familias y cómo se sienten seguras en sus hogares y bienvenidos en nuestra propia nación". 3

La determinación del juez Souter de retirarse ocurrió en medio de la tormenta provocada por la aparición del virus A H1N1, a unos días de la conmemoración de los primeros 100 días del nuevo gobierno, en medio de la peor crisis económica y conflictos financieros y crediticios desde la Gran Depresión, al tiempo que se desarrollan dos guerras (Irak y Afganistán) y al momento de decisiones sobre el futuro de algunas de las em-

1 Tobin, Jeffrey, The Nine, Inside the Secret World of the Supreme Court, Nueva York, Doubleday, 2007, p. 3.

2 Utilizaré la expresión juez para referirme al juez asociado, justice. El presidente de la Suprema Corte los Estados Unidos es denominado chief justice.

3 "Washington Prepares for Fight Over Any Nominee", The New York Times, 2 de mayo de 2009. 
presas más importantes de los Estados Unidos, particularmente las productoras de automóviles General Motors y Chrysler. La decisión de que Chrysler, la tercera productora de automóviles se fuera a la quiebra, ocurrió prácticamente al mismo tiempo que el anuncio de la futura inmediata vacante de la Suprema Corte. Las noticias alrededor de la vacante del juez han ocupado prácticamente los mismos espacios que las demás noticias de atención mundial. ${ }^{4}$

La quiebras de Chrysler y particularmente de General Motors ha planteado un tema ideológico en el debate político de los Estados Unidos. Las productoras de automóviles se han significado como íconos del sistema capitalista. La protección que se dará a los acreedores de Chrysler, en términos del capítulo 11,5 modificará la participación de los propietarios de la empresa, sujeta a la reorganización, de tal manera que ahora la mayoría estará a cargo de los fondos de los trabajadores y de manera minoritaria en el propio gobierno de los Estados Unidos, que ha aportado cuantiosos recursos fiscales y de la empresa italiana Fiat. De igual manera, el arreglo para la restructuración de General Motors, en que los gobiernos de Canadá y Estados Unidos participarán como accionistas junto con el Sindicato de Trabajadores de la Industria Automotriz, rompe con las reglas básicas del capitalismo tradicional. Es evidente que las reglas del capitalismo ortodoxo se han modificado. El derrotero que han tomado estas empresas ha puesto en la mesa un debate ideológico sobre el papel intervencionista o no del Estado en la Unión Americana. Es previsible que éstos y otros temas sobre el papel del Estado en la economía y la intervención estatal en temas tradicionalmente sujetos únicamente a las leyes del mercado, sean asuntos que atenderá la Suprema Corte de Justicia.

La designación del sucesor del juez Souter, el primer nombramiento que hará el presidente Obama de un integrante de la Suprema Corte de Justicia de los Estados Unidos ocurre en esta atmósfera y estará cargada de elementos ideológicos, sociológicos, económicos y políticos.

4 Ejemplo de la cultura constitucional en los Estados Unidos.

5 El capítulo 11 del Código de Bancarrotas de los Estados Unidos permite una reorganización de una empresa en lugar de una liquidación. Consiste en la formulación de un plan en el que estén de acuerdo las partes interesadas en la quiebra a fin de llegar a acuerdos favorables para todos, bajo la conducción de un juez especial. 


\section{LA IDEOLOGÍA EN LAS DESIGNACIONES JUDICIALES}

El enorme interés que provocó en la opinión pública estadounidense y en la arena política la vacante de Souter, deriva de la significación que tiene la composición ideológica de la Corte de los Estados Unidos. La designación de Souter hace 20 años tuvo también ese mismo origen y sentido. El presidente George H. W. Bush designó a David H. Souter por un supuesto conservadurismo y afinidad con la derecha que encarna el Partido Republicano. A final de cuentas, el juez Souter demostró no tener agenda política, ni se integró al equipo de cuatro conservadores de la extrema derecha, los jueces Clarence Thomas, Samuel A. Alito Jr., Antonio Scalia y el propio presidente de la Suprema Corte John G. Roberts Jr. Souter será reconocido por los liberales y despreciado por los conservadores. Los primeros le agradecen haberse convertido en un aliado inesperado de sus causas, los segundos no le perdonan haberlos traicionado, dicen ellos en forma específica con el tema del aborto. Souter será recordado como un juez dedicado y un extraordinario ser humano. La desilusión que su desempeño en cuestiones claves causó en el presidente George W. Bush, motivó la expresión "no más Souters". Su venganza fue la designación de conservadores con agenda, como han sido los jueces John G. Roberts y Samuel Alito, reputados por los republicanos como ideológicamente confiables. ${ }^{6}$ Un elemento interesante es que durante la confirmación senatorial del chief justice John G. Roberts el senador Obama votó en contra de su nominación con otros 22 senadores en una cámara compuesta por 44 demócratas. Trató por otra parte infructuosamente de bloquear la nominación de Samuel Alito, en un intento acompañado por otros 25 senadores demócratas. ${ }^{7}$

Si nos remontamos al origen de las nominaciones judiciales hechas por los presidentes siempre ha estado presente un elemento político. George Washington, el único presidente que tuvo la facultad de nombrar a todos los jueces de la Suprema Corte, incluyendo a su presidente marcó dos tradiciones: inició la práctica de designar a quienes tuvieran empatía política con el presidente, y trató de establecer algún equilibrio en la composición del alto tribunal. Washington lo hizo a partir de la oriundez

6 Rosen, Jeffrey, "The Stealth Justice”, The New York Times, 2 de mayo de 2009.

7 Charlie, Savage, "Scouring Obama's Past For Clues On Judiciary", The New York Times, 10 de mayo de 2009. 
de los jueces. De sus primeros seis designados a la Suprema Corte incluyó a tres sureños y a tres norteños. ${ }^{8}$ Más adelante habría otras cuestiones a considerar además del origen territorial, como el género y la raza.

La selección de Souter por el presidente George H. W. Bush en 1990, se explica por tratarse de un juez de apelación, con apenas dos meses en funciones. Se ha dicho que su breve gestión impidió al Comité Senatorial conocer el sentido ideológico de las resoluciones de Souter, lo que hacía difícil impugnar su propuesta. El problema es que el plan, aparentemente perfecto de contar con un aliado en el alto tribunal, se volvió contraproducente. El grupo de luchadores antiaborto, los pro-vida, habían abrigado la esperanza de que Souter echara abajo la decisión tomada en 1973 en el célebre caso de Roe vs. Wade. Sin embargo, quedaron frustrados. Stouter en contra de lo esperado confirmó en 1992, la decisión sobre el derecho al aborto.

Por otra parte, el mismo año se unió a la mayoría de cinco contra cuatro para confirmar la decisión de prohibir los rezos en las escuelas. En el año 2000 Souter votó en contra de otorgar automáticamente la presidencia al hijo de quien lo designó miembro de la Suprema Corte en Bush vs. Gore. En ese caso, Souter estuvo del lado de quienes perdieron y se ha escrito que estuvo a punto de renunciar. ${ }^{9}$

Aun cuando no se pretende describir con detalle la manera en que la Corte de los Estados Unidos ha ido perfilando sus decisiones con fundamento en elementos ideológicos, la importancia de sus decisiones en la vida política, económica y social es determinante, por lo que su conformación puede sugerir algún derrotero de la políticas públicas. Por ello es que la expectativa primero de conocer quién sería designado como sucesor del juez Souter y después - ya seleccionado- imaginar cómo actuará, reviste una destacada importancia. La Suprema Corte al interpretar la Constitución fija la ruta ideológica del sistema en su conjunto. Esa decisión la señala la mayoría, generalmente por un solo voto. Las decisiones fundamentales que han sido adoptadas durante decenios sobre temas de significación social, económica, religiosa y política son susceptibles de

8 Carp, Robert A. y Stidham, Ronald, Judicial Process in America, 3a. ed., Washington, Congressional Quaterly Press, 1975, p. 25.

9 A pesar de ser un hombre rico, Souter es considerado un anacoreta. Dice de sí mismo que es un enamorado de la impartición de justicia, pero que odia vivir en Washington. "Following Souter", The Economist, 7 de mayo de 2009. 
modificarse y en ese sentido cuestiones como libertades fundamentales, igualdad de géneros, derechos de las minorías, libertad o no sobre el aborto, la libertad de conciencia, la religión, el matrimonio entre personas del mismo sexo dependen del voto de cinco jueces.

Obama es un presidente popular que tiene a la mayoría del Senado de su lado, en tanto este cuerpo legislativo está integrado mayoritariamente por demócratas. Es altamente probable que el Senado ratifique el nombramiento que hará de la jueza Sonia Sotomayor. Sin embargo, la fortuna política está de su lado. Unos días antes de la decisión de Souter de retirarse, el presidente Obama celebró con el Partido Demócrata la incorporación del senador Arlen Specter, quien había sido un leal republicano. Las razones de Specter para dejar el Partido Republicano fueron de carácter ideológico, pues se encontró cada vez más en oposición a la postura de su anterior partido. "Estoy poniendo los principios por delante", declaró el senador y agregó que cada vez que el Partido Republicano se va más a la derecha, él se ubica más cerca de los demócratas. Se estima que con ese voto Obama no tendrá problema en que su candidato a la Suprema Corte sea confirmado por el Senado. Los demócratas tienen 60 de los 100 votos del Senado. Sin embargo, al ser la sustitución del juez Souter la primera designación, es previsible que traté de lograr el consenso y no polarizar la designación.

Como la ideología es algo intangible y eventualmente cambiante, los presidentes en Estados Unidos han decidido nombrar jueces federales, con carrera judicial, que les permitan tener una guía sobre el sentido ideológico y consecuencias políticas, las decisiones que han tomado analizando el sentido de sus votos. De hecho se da la histórica circunstancia de que la actual Suprema Corte está integrada exclusivamente por quienes fungieron previamente como jueces de apelación en las cortes federales. ${ }^{10}$

Se han producido algunas investigaciones académicas que pretenden demostrar la trayectoria ideológica de los integrantes de la Suprema Corte. Tales análisis intentan descubrir el sentido de los votos en cuestiones

10 Los jueces de apelación son equivalentes a los magistrados de circuito del Poder Judicial de la Federación en México. De los jueces de la Suprema Corte en funciones siete fueron jueces de apelación en el circuito de Acela en Boston, Filadelfia y Washington. Las excepciones son los jueces John Paul Stevens, quien estuvo adscrito en Chicago y Anthony Kennedy en California. Esto último hace sentir que haya una preeminencia de jueces del Este, en el denominado corredor Washington-Cambridge-New Haven. 
determinadas, a partir de decisiones anteriores. Finalmente el dilema es precisar si los jueces de la Suprema Corte mantienen una posición ideológica durante su historial judicial o si el tiempo modifica sus criterios en temas en que se deben fijar posiciones y criterios. Existe la idea generalizada de que los jueces no cambian sus posiciones o principios filosóficos y que la doctrina que adoptan será su línea inamovible durante su gestión. Uno de esos estudios, que revisó la actuación de los jueces de la Corte de Roberts, ha llegado a la conclusión de que sí existe cambio doctrinal en la actuación de los jueces y no la inercia que simple vista podría esperarse de sus perfiles, formación y posición ideológica o política. ${ }^{11}$

Conforme a una visión tradicional es improbable que existan cambios de criterio de un órgano jurisdiccional que mantenga a los mismos integrantes o, dicho de otra manera, el cambio de criterio o de postura ideológica sólo es posible si se da un cambio en la composición de los integrantes de un órgano jurisdiccional. El tema es discutible y provoca un sinnúmero de anécdotas que tratan de demostrar en el terreno de lo empírico que los jueces, como todos los seres humanos, cambian con el tiempo. El sentido hacia donde ocurre el cambio es naturalmente imprevisible. Lo que no queda totalmente claro es si todos cambian con el tiempo y el sentido del cambio, esto es además de la eventualidad de cambiar, si confirman o hasta radicalizan sus posiciones y criterios. El juez Harry Blackmun ha declarado que es la Corte y no él, la que adptó nuevos criterios y posturas ideológicas, "No creo que sea más liberal ahora de lo que fui alguna vez", le dijo Blackmun a un reportero. Muchos analistas están en desacuerdo pues no pueden creer que sea el mismo Blackmun el que en 1972, disintió de la decisión en Furman vs. Georgia que echó abajo algunas leyes sobre la pena de muerte, el mismo que en otro voto particular en 1994, disintió en Callins vs. Collins al escribir que: "De ahora en adelante ya nunca más experimentaré con la maquinaria de la muerte". ${ }^{12}$

Hay quienes afirman que prácticamente todos y cada uno de los jueces de la Suprema Corte de Justicia que han estado en funciones desde 1930,

11 Epstein, Lee et al., "Ideological Drift among Suprem Court Justices: Who, When and How Important", Norwhwestern University Law Review, 127 (2007), vol. 101, Issue 4, pp. 1483-1542, y la respuesta a este trabajo en la misma publicación, Greenhouse, Linda, "Justices Who Change; a Response to Epstein et al., Colloquy", pp. 1885-1890.

12 Ibidem, pp. 1485-1486. 
se han ido de la (posición) izquierda a la derecha y en algunos casos han cambiado de postura ideológica en varias ocasiones. Lo anterior no es un divertimiento intelectual. Los cambios ideológicos han tenido repercusiones legales importantes y han propiciado un cambio jurisprudencial en los criterios del máximo tribunal de ese país. Estos cambios son indicadores además del carácter o temperamento judicial.

\section{EL TEMPERAMENTO JUDICIAL}

El temperamento judicial juega un papel muy relevante y no tiene que ver necesariamente con una ideología. Los rasgos personales de los juzgadores, su personalidad, carácter, hábitos, entorno familiar y social, origen socioeconómico, racial, formación académica, antecedentes entre otros muchos factores juegan un papel en la configuración del temperamento de un tribunal. En los Estados Unidos - y esto acontece también en México y seguramente en muchas otras partes del mundo- los juzgadores responden a factores desconocidos, propios de la naturaleza humana. Hay jueces individualistas que están más preocupados por su historia personal y por llamar la atención que por formar equipo con sus colegas. Hay otros por el contrario que estarían dispuestos a dejar su agenda política y en ocasiones hasta sus convicciones ideológicas por el bien de la justicia que se imparte la Corte.

Jeffrey Rosen hace una comparación de temperamentos judiciales para medir la influencia de éstos en las decisiones judiciales. Una de las decisiones cruciales del siglo XX fue la de Brown vs. Board of Education. Esta resolución se gestó durante la presidencia de Fred Vinson, pero correspondió al chief justice Earl Warren hacer todo lo necesario para asumirla. ${ }^{13}$

En 1952, cuando Vinson era el presidente de la Suprema Corte, contaba con cuatro votos asegurados para cancelar la segregación en las escuelas públicas. El líder para mantener el estado de cosas y no modificar una política tan importante fue el propio presidente Vinson. Antes de ser designado Vinson había impresionado al presidente Truman como un diestro secretario del Tesoro y magnífico jugador de póker. Se decía que es-

13 Esta decisión canceló la política de "separados pero iguales" fijada en Plessy vs. Ferguson, que durante decenios convalidó la segregación racial en los Estados Unidos, particularmente en los estados esclavistas. 
tas eran las credenciales por las cuales fue nombrado. Truman esperaba que Vinson resolviera los problemas de temperamento en la Suprema Corte. El problema es que Vinson era considerado un político de mano dura antes que un buen mediador. El juez Félix Frankfurter, con notables dotes intelectuales, lo menospreciaba públicamente al grado de que Vinson lo amenazó en una reunión pública con darle un puñetazo en la nariz. Bajo la presidencia de Vinson fue imposible que la Corte llegara a un consenso en el caso de Brown y el asunto se llevó hasta el año siguiente (1953). Vinson murió inesperadamente antes de que su término concluyera. ${ }^{14}$

A Vinson lo sustituyó en la presidencia de la Suprema Corte, Earl Warren, el ex gobernador durante tres periodos de California, notable político que logró la nominación de su candidatura a gobernador, tanto por los demócratas como por los republicanos. Warren además fue nominado por el Partido Republicano candidato a la vicepresidencia. Warren logró el consenso a pesar de no contar con antecedentes judiciales ni ser jurisperito. Su consideración con los demás, modestia y trato respetuoso con sus colegas jueces le permitió alcanzar el consenso. En privado comentó con ellos que la segregación racial era algo inmoral y estaba sustentada en la premisa inmoral de que la raza negra es inferior. El consentimiento de todos para lograr la unanimidad era crucial, pues un solo voto en contra generaría la resistencia política de los estados del sur que verían caer sus pretensiones de mantener la segregación en sus territorios. Warren tuvo la capacidad política y la autoridad moral para que el juez sureño Stanley Reed, en un principio reacio a votar con la mayoría, decidiera finalmente dar su voto para lograr el consenso.

Otro voto en esta decisión crucial fue el de Hugo Black, juez designado por el presidente Fraklin D. Roosevelt. Black inicio su carrera política como miembro del $\mathrm{Ku}$ Klux Klan, organización que favoreció y tal vez fue determinante para que llegar al Senado por Alabama. Black ocultó al presidente Roosevelt su membresía a la agrupación clandestina, y como senador que era fue ratificado como juez de la Suprema Corte en una semana. El escándalo estalló una vez que había sido designado juez de la Suprema Corte. Los ataques de que fue objeto lo marcaron de por vida y hay quien explica su voto en contra de "separados pero iguales" y a favor

14 En el tren de regresó a su casa, después del funeral de Vinson, el juez Frankfurter declaró que "esta es la primera indicación que tenía de que efectivamente existía Dios". 
de la integración como un deseo de autoabsolución respecto al tache de racista que llevaría como lápida toda su vida. Black se convirtió después en un indeclinable defensor de los derechos humanos. Argumentó que el significado original de la Enmienda 14 sobre la garantía de igualdad no podría jamás significar que separados significara iguales. Black fue el más decidido promotor de la integración racial por orden judicial, si bien sabía por sus antecedentes que el Sur combatiría esta política. ${ }^{15}$ Ese voto le dio a la Suprema Corte un carácter y temperamento que le permitiría más adelante resolver con toda autoridad y majestad asuntos que fijarían el derrotero político, económico, social y religioso de los Estados Unidos.

A partir de la decisión en Brown vs. Board of Education, la Suprema Corte de los Estados Unidos encontró su temperamento como defensora de los derechos humanos y las mejores causas sociales. No debe olvidarse que antes de esa histórica decisión la Suprema Corte tuvo aciertos, particularmente respecto a la división de poderes, pero también cometió graves errores. La Suprema Corte de los Estados Unidos no hizo nada por evitar la esclavitud, sino que por el contrario emitió la oprobiosa decisión en Dred Scott (1854) que prendió el fuego de la sangrienta Guerra Civil y además institucionalizó los horrores de la esclavitud. ${ }^{16}$ El criterio sustentado en esta resolución duró más de 100 años institucionalizando un trato racista y discriminatorio.

Los Estados Unidos esperan algunas decisiones relevantes en materias como el aborto, matrimonio entre personas del mismo sexo, derechos electorales (Voting Rights Act). Sin embargo estos asuntos tradicionales, si bien relevantes, no son los que preocupan en primer término al gobierno, excepción hecha del aborto, sino aquellos que derivan de la crisis económica que habrán de llegar a la Suprema Corte. Tiene que ver con la participación cada vez más activa y la intervención más decidida del go-

15 Feldman, Noah, "When Arrogance Takes the Bench", The New York Times, 10 de junio de 2009.

16 Dred Scott fue un esclavo que vivía en territorios donde la esclavitud era ilegal. Al plantear su caso de emancipación ante la Suprema Corte, ésta resolvió en una decisión siete a dos, que nadie de origen africano podía aspirar a la ciudadanía estadounidense y por tanto estaba impedido para acudir a un tribunal federal. En el fondo, la decisión de la Suprema Corte permitía a un blanco propietario de esclavos comprarlos en un estado esclavista y traerlos a un estado donde la esclavitud fuera ilegal, sin perder los derechos sobre tales esclavos. Este fue el detonador de la guerra entre Sur y Norte. 
bierno en la economía y en la operación mercantil de negocios relacionados con la banca, las compañías aseguradoras, los negocios inmobiliarios o la industria automotriz, así como la persecución de delincuentes de cuello blanco, a quienes se les culpa en buena medida de la recesión y crisis económicas.

La posición ideológica en estos asuntos, como en el tema del aborto, es tajante. Quienes piensan que el Estado debe mantenerse estrictamente en el ámbito de su tarea como guardián del orden y seguridad interior, capaz de ejercer la hegemonía económica, militar y política frente al mundo exterior y garantizar de las libertades de libre empresa, librecambio y libre competencia y quienes estiman, por el contrario, que es necesaria una mayor regulación, protección e intervención estatal que impida las recesiones económicas o los abusos de una clase empresarial ávida de ganancias al costo moral y ético que resulte. Por ello se espera que el presidente Obama, al sustituir al juez Souter y al designar a la jueza Sotomayor, fortalezca al grupo liberal de la Suprema Corte y de esa manera sus propias políticas públicas y agenda política.

Lo anterior pone en tela de juicio la idea de que los jueces deben ser seres neutros políticamente y solamente atender las cuestiones que se les planteen con una venda en los ojos. La pregunta en realidad es si la Suprema Corte de los Estados Unidos tiene o debe tener un temperamento neutro o ideológico. ¿Debe la Suprema Corte ser un factor de cambio? ¿Lo debe ser de estabilidad institucional? Para cumplir mejor su cometido ¿Debe su presidente tratar de alcanzar decisiones unánimes? ¿Las decisiones unánimes fortalecen o debilitan a una corte suprema?

John Roberts, el actual presidente de la Suprema Corte, definió el temperamento judicial como la voluntad de dejar atrás los puntos personales de vista con los que se está comprometido en la función judicial y evaluarlos en términos del papel que se desempeña como juez. El chief justice Roberts señaló en una entrevista que el temperamento judicial es la diferencia entre ser juez y profesor de derecho, y que no se trata tanto de una cuestión de coherencia o perspectiva analítica, es más bien si una cuestión determinada es compatible con el cuerpo normativo establecido por la Corte. Además, cómo tal cuestión será apreciada como derecho. ${ }^{17}$

Alcanzar la unanimidad o el consenso como sistema de trabajo en un órgano jurisdiccional es una ilusión y tiene que ver con el temperamento

17 Carp, Robert A. y Stidham, Ronald, op. cit., nota 8, pp. 7 y 8. 
del órgano jurisdiccional. Una de las garantía, judiciales esenciales como la de independencia impide la unanimidad como sistema. John Marshall, el legendario presidente de la Suprema Corte que emitió la resolución más relevante de todas las que se han emitido, al preservar la facultad judicial de determinar la constitucionalidad de los actos del Congreso, tuvo como mira durante su presidencia, mantener el disentimiento a su nivel más bajo. Argumentaba que el disentimiento mina la autoridad de la Corte y por tanto trató de convencer a los jueces que resolvieran sus diferencias en privado y después presentarán un frente común al público. En aquellos días, al inicio del siglo XIX, los jueces de la Suprema Corte, mientras estaban es sesión, vivían bajo el mismo techo, en la misma casa de huéspedes en la ciudad de Washington. Esta idea puede prevalecer en algunas cortes en las que el liderazgo del presidente sea de tal naturaleza que los jueces se consideren integrantes de un equipo unitario. La independencia judicial y la diversidad de criterios y enfoques hace prácticamente imposible que esto ocurra.

El presidente de la actual Suprema Corte de Justicia John G. Roberts pretendió lograr la unanimidad colegiada de la Corte. Tuvo mucha suerte en su intento, pues bajo su liderazgo, en su primer término, la Corte emitió más resoluciones concertadas y expresadas en forma unánime que en cualquier otro momento de los tiempos contemporáneos. No obstante, Roberts no estuvo satisfecho y llegó a expresar que si el presidente de la Corte John Marsahll hubiera tenido la Corte que ha existido en los últimos treinta años, hubiera sido imposible disponer de una suprema corte como la actual. El final de su primer término fue caracterizado por el juez John Paul Stevens como una "cacofonía" de voces discordantes, con jueces en oposición sistemática, refiriéndose en términos personales respecto de sus colegas de tribunal en términos inusuales.

Roberts estimó que la Suprema Corte tendría que encontrar una nueva manera de funcionar institucionalmente. Hizo el compromiso de evitar que sus colegas formularan opiniones, o votos particulares, separados. "Creo que cada juez debería estar preocupado por la Corte en su actuación como tribunal y funcionamiento como tribunal. Deberían estar preocupados al formular votos particulares, por el efecto que éstos tienen sobre la Corte como institución". ${ }^{18}$ 


\section{LA DESIGNACIÓN DE LA JUEZA SOTOMAYOR}

La decisión del juez Souter al dejar el cargo provocó un interés mayúsculo por conocer la persona que habría de ser designada como integrante de la Suprema Corte de Justicia de los Estados Unidos. El interés deriva de la significación que puede tener el criterio del integrante de la Corte en razón de la división tan marcada entre quienes son considerados conservadores y quienes tienen un perfil más de apertura, proclive al cambio social y avanzada.

La jueza Sonia Sotomayor será la tercera mujer en ocupar el cargo en la historia del Tribunal, la primera hispana en ser designada y actualmente la segunda mujer en la actual integración de la Corte. La designación constituye un asunto de la mayor relevancia política. Al hacer el anuncio, el presidente Obama avisó a los precandidatos que habían sido señalados, junto con Sotomayor, a ocupar el alto cargo que había tomado la decisión de optar por la jueza Sotomayor. De esta manera llamó a los otros finalistas: la jueza Diane P. Wood de Chicago, la secretaria de Seguridad Nacional Janet Napolitano y la abogada general de los Estados Unidos ante la Suprema Corte Elena Kagan, para agradecerles su disposición a ser considerados en la evaluación y auscultación de sus credenciales.

La polarización que generó la nominación de Sotomayor entre quienes la apoyan y quienes se muestran en contra de su designación es de carácter eminentemente político. Los conservadores estiman que es una activista judicial y que tiene una agenda política que impediría la aplicación de la ley de manera objetiva, imparcial y justa. Naturalmente se oponen a su designación. La posición de la prensa estadounidense es ilustrativa de lo anterior. The New York Times, de tendencia liberal, saludó la nominación con su editorial que señaló la inminente confirmación del Senado a fin de que se integre a la Suprema Corte a partir del nuevo periodo de octubre. No obstante, The Wall Street Journal, si bien acepta que un presidente popular, como Obama, con 50 votos en el Senado puede lograr que su nominación sea confirmada por el Senado, los republicanos pueden utilizar el proceso de ratificación, no para denigrar a la nominada con base en cuestiones personales, como la izquierda lo hizo antes con los jueces Clarence Thomas y Sam Alito, "sino para educar a los americanos acerca del papel apropiado que debe desempeñar la judicatura para investigar si los principios constitucionales de la jueza Sotomayor son tan 
formalmente liberales, como parece derivar de su récord". The Washington Post, de la misma tendencia, señaló en su editorial que los senadores tienen el derecho de escrudiñar la filosofía y calificaciones de la jueza Sotomayor. Como jueza de apelación que ha sido, ha de producir un importante expediente de opiniones judiciales que el Comité podrá discur tir. ${ }^{19}$

Sotomayor fue designada por el presidente George H. W. Bush como jueza de distrito en 1992. Más adelante, el presidente Clinton la ascendió a juez de apelaciones en 1998. Los antecedentes más notables que se han dado a conocer a la opinión pública sobre la futura jueza de la Suprema Corte son que nació en un barrio popular del Bronx, en Nueva York y que fue una extraordinaria estudiante con honores de las mejores universidades en Estados Unidos como Princeton y Yale. Igual que el presidente Obama lo hizo con la revista de Harvard, Sotomayor fue la editora de la prestigiosa Yale Law Review.

No obstante hay un dato de mayor interés, pues se trataría, de ser confirmada, de la jueza de la Suprema Corte de los Estados Unidos con más experiencia judicial federal en un siglo y con mayor experiencia judicial en general en setenta años. Su expediente laboral indica que ha participado en 3,000 discusiones en paneles y ha emitido cerca de 400 opiniones sobre intrincados temas de derecho constitucional, cuestiones de procedimiento o demandas legales relativas a cuestiones de derecho mercantil. Sin embargo, el dato más ponderado ha sido que su sentido común para el análisis jurídico y que nunca ha dejado de seguir el criterio de revisar de qué manera la ley afecta la vida cotidiana, hace de la jueza Sotomayor, dice el gobierno que la propone, la mejor opción. Por supuesto que los conservadores no están de acuerdo con el criterio y son precisamente sus cualidades exaltadas por los demócratas las que se vuelven defectos para ejercer la función jurisdiccional. La inminente confirmación de la jueza Sotomayor mantiene la circunstancia de que la actual Suprema Corte de los Estados Unidos está integrada exclusivamente por jueces que se habían desempeñado como funcionarios judiciales antes de ser designados.

19 Artículos editoriales de The New York Times, The Wall Street Journal, The Washington Post, 26 de mayo de 2009. 


\section{LAS PERSPECTIVAS DE LA SUPREMA CORTE EN LA ERA DE OBAMA}

La confirmación de la juez Sonia Sotomayor como integrante de la Suprema Corte de Justicia de los Estados Unidos ha generado una amplia serie de especulaciones sobre la política judicial de los próximos años. Las cuestiones sustantivas que podrían alterarse son las que integran la agenda política, social, económica y religiosa de los Estados Unidos.

En materia política el sector conservador de la Corte se ha opuesto sistemáticamente a una revisión de la ley sobre derechos electorales de los Estados Unidos (Voting Rights Act). Al término de la Guerra de Secesión, la Enmienda 14 consignó que los negros tienen iguales derechos. La Enmienda 15 por su parte expresó que el derecho al sufragio no puede limitar o condicionar por razones de raza. Estas enmiendas constitucionales le dieron al Congreso de los Estados Unidos el fundamento para expedir la legislación correspondiente. Después del movimiento de los derechos civiles de los años cincuenta y sesenta, el Congreso expidió la ley sobre derechos electorales de los Estados Unidos (Voting Rights Act) en 1965. Esta ley consideró cuestiones como determinar ilegales las pruebas para limitar el voto de los analfabetas o evitar los impuestos electorales. La Suprema Corte consideró la validez de la ley a un año de haberse expedido (1966) y lo ha hecho en tres ocasiones adicionales. El Congreso ha mantenido el sentido de la ley sin alterarla y de igual manera lo han hecho los presidentes que han refrendado su aplicación y vigencia. Antes de renovar la ley en 2006, el Congreso llevó a cabo 21 audiencias y reunió miles de testimonios para determinar el derrotero de la ley. El Senado votó 98-0 a favor de una renovación de la ley y el presidente George W. Bush firmó la Voting Rights Act. Esta ley se ha enfrentado a la posición conservadora y llamada "federalista" de un grupo de jueces de la Suprema Corte que estiman que el Congreso no tiene por qué legislar y fijar reglas electorales aplicables a los estados. El presidente de la Corte, el chief justice Roberts ha declarado por ejemplo estar inconforme con que la ley se aplique más en estados del Sur que del Norte. El juez Scalia, otro conservador, piensa que el en el estado de Virginia no debe- 
ría aplicarse la ley, toda vez que "fue el primer estado en elegir a un gobernador negro". ${ }^{20}$

Otro tema de especial importancia para la Corte de Obama es el relativo al aborto. El desarrollo jurisprudencial ha mostrado lo irreconciliable de las posiciones sobre el derecho a la vida por un lado y el derecho a la libertad de elección de la madre embarazada. Con el avance de la medicina, al final del siglo XIX, se expidieron leyes en contra del aborto fundamentalmente para proteger la salud de las mujeres. Otras disposiciones legales consideraron prohibir algunos anticonceptivos y abortivos como parte de una estrategia legal contra "la obscenidad". Más adelante, se impulso el control de la natalidad y para la década de los sesenta, en el siglo pasado, 48 estados habían legalizado el control de la natalidad. A pesar de el avance en las medidas anticonceptivas, tanto desde un punto vista moral, técnico sanitario y jurídico, las mujeres enfrentaban embarazos no deseados y el aborto constituía una forma segura de control natal. Sin embargo, el aborto es un asunto mucho más controversial y complicado que la utilización y autorización de los métodos tradicionales de control natal.

Para 1960, el aborto era ilegal en los Estados Unidos, excepto para salvar la vida de la mujer embarazada. El movimiento feminista de los Estados Unidos impulsó decididamente el movimiento del derecho al aborto. Desde entonces se ha dado un importante desarrollo legal sobre el tema y su consecuente respuesta jurisprudencial. El caso clásico es el de Roe vs. Wade, antes mencionado, en que la Suprema Corte de Estados Unidos en 1973, en una decisión mayoritaria de siete votos estableció que "el derecho a la privacidad es tan amplio como para incluir la decisión de una mujer de terminar o no con su embarazo". La opinión mayoritaria del juez Harry Blackmun generó después muchas controversias. Entre otras cosas decía que que el Estado podría imponer una carga en detrimento de la mujer embarazada y "el sufrimiento para todos los relacionados con un niño no deseado". Éstos y otros argumentos fueron considerados, tanto por quienes están a favor como en contra del aborto, por estimar que no tienen sustento suficiente y por su pobreza argumentativa. Blackmun expresó por ejemplo que los fetos no son seres humanos y que el derecho estadounidense no haconsiderado a los nonatos como perso-

20 Adam, Cohen, "The Supreme Court's Hostility to the Voting Rights Act", The New York Times, 13 de mayo de 2009. 
nas. La decisión judicial en Roe fijaba ciertas reglas: el Estado podría restringir el aborto, cuando esto fuera necesario, para proteger las salud de la madre. Las restricciones también podrían aplicarse en diversos momentos del embarazo, la salud materna al final del tercer mes, la vida en potencia al final del sexto. De esta manera el derecho al aborto estaba limitado. Durante el primer trimestre el Estado no tenía derecho alguno para restringir el aborto, a partir del segundo trimestre el Estado podría regular pero no prohibir el aborto y en el tercer trimestre el Estado podría prohibir el aborto, excepto si la salud de la madre estuviera en riesgo. ${ }^{21}$

Una de las figuras centrales en el tema del aborto es la jueza Sandra Day O'Connor. Antes de ser designada como jueza de la Suprema Corte tuvo experiencia legislativa en Arizona, su su estado natal, en donde le correspondió participar en la creación de leyes sobre el aborto. En Arizona la ley prohibía el aborto, excepción hecha del aborto terapéutico. La senadora O’Connor participó, según un periódico local, en un comité que despenalizaría el aborto. La medida pasó al tamiz de la comisión senatorial pero nunca llegó al pleno. Si bien apoyó la medida pro-aborto, también respaldó ciertas restricciones a los derechos para abortar. Lo hizo a través de una ley que establecía la prohibición para practicar abortos a médicos que no estuvieran facultados por su licencia para ejercer la profesión médica. En esos días ocurrió la decisión en Roe vs. Wade que protegió constitucionalmente el aborto y el debate sobre el tema desapareció de la agenda política de Arizona. Jeffrey Tobin refiere este pasaje de la vida política de O'Connor pues durante el proceso de escrutinio sobre sus antecedentes, al considerada para ser nominada como jueza asociada de la Suprema Corte de los Estados Unidos por el presidente Ronald Reagan, nunca apareció el periódico de Arizona y ella garantizó al presidente - quien finalmente la designaría — que "personalmente" se oponía al aborto y dejó una sensación ambigua sobre su percepción de los derechos de las mujeres al aborto. ${ }^{22}$

Una de las candidatas que la prensa mencionó como viable sustituta del juez Souter fue Sonia Sotomayor. Al final de un escrutinio entre personajes de la vida jurídica y política de Estados Unidos, el presidente Obama decidió por esta mujer, hispana con antecedentes liberales. En el

21 Kermit L., Hall (ed.), The Oxford Companion to the Supreme Court of the United States, voz: “Abortion", pp. 3 y 4.

22 Tobin, Jeffrey, op. cit., nota 1, pp. 39 y 40. 
anuncio de su propuesta Obama dijo que generalmente los jueces federales y de las cortes de apelación no tienen mucha exposición pública a nivel nacional y no son figuras políticas. No obstante, la jueza Sotomayor resolvió una controversia en una famosa huelga que estuvo a punto de cancelar una temporada de beisbol profesional de Grandes Ligas, el pasatiempo nacional en los Estados Unidos. Al haber fallado a favor de los jugadores y consecuentemente en contra de los propietarios de los equipos y haber salvado la temporada deportiva, la convirtieron en una figura nacional. La jueza Sotomayor es hija de inmigrantes puertorriqueños y tendría además de sus propias credenciales judiciales, el ser mujer y miembro de la minoría hispana. En 2001, hace ocho años, pronunció un discurso que ha entrado al debate en razón de que en el mismo afirmó que la etnicidad y el género de un juez pueden marcar la diferencia a la hora de emitir una resolución. Lo anterior para algunos críticos rompe con el principio de la imparcialidad y objetividad que debe observar un juez. En tal discurso que ahora con su nominación se ha vuelto famoso, puso en tela de juicio un famoso argumento planteado por la jueza Ruth Bader Ginsburg y por la jueza asociada de la Suprema Corte Sandra Day O'Connor, de que un hombre viejo y sabio y una mujer vieja y sabia llegarían a la misma conclusión al resolver un caso en la corte. La jueza Sotomayor dijo por el contrario que "esperaría que una mujer latina, con la riqueza de su experiencia llegaría a una mejor conclusión que un hombre blanco que no ha vivido tales experiencias". Recientemente (2005) dijo en una reunión con estudiantes de derecho que pretendían convertirse en secretarios judiciales, que las cortes de apelación son los lugares donde se hacen políticas públicas. Agregó inmediatamente, como lo muestra la grabación de video donde están contenidas estas declaraciones, que sabía bien que eso era algo que nunca debió haber dicho, porque ellos en el juzgado de apelación, no hacen leyes. ${ }^{23}$

Lo interesante resulta además el escrutinio que los medios y la opinión pública hicieron de los antecedentes, primero de los candidatos a ocupar la vacante que quedara cuando Souter deje el sitial y ahora de la jueza nominada por el presidente Obama para ocupar tal vacante.

Con seguridad la jueza Sonia Sotomayor habrá de integrarse a la Suprema Corte de Justicia, una vez que sea ratificada por el Senado. Es pre-

23 Lewis, Neil A, "A Résumé Including «Baseball Savior»”, y Savage, Charlie, "A Judge's View of Judging Is on the Road”, The New York Times, 15 de mayo de 2009. 
sumible que ocurran otras vacantes en la Suprema Corte, toda vez que la edad avanzada de uno de ellos y el estado de salud de otro, podrían sugerir que ocurran otras vacantes durante la gestión presidencial. ${ }^{24}$ De darse vacantes habrá nuevamente turbulencia y tensión en el ambiente político, social, jurídico, académico y económico de los Estados Unidos. Es altamente probable que el presidente Obama trate de orientar ideológicamente sus propuestas al Senado. Tendrá que cuidar que sus decisiones obtengan el consenso mayoritario, lo que redundará en la actuación y temperamento de la futura Suprema Corte de Estados Unidos, la que la historia reconocerá como la Suprema Corte de Obama.

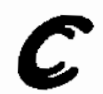

24 El juez John Paul Stevens nació en 1920 y la jueza Ruth Bader Ginsburg padece cáncer de páncreas. 